\title{
PERANCANGAN KOMIK ANDHE ANDHE LUMUT BERDASARKAN RELIEF KISAH PANJI DI KOMPLEKS CANDI PENATARAN
}

\author{
Tegar Andito \\ Tenaga Pengajar Program Studi Desain Komunikasi Visual \\ Fakultas Sains dan Teknologi, Universitas Ma Chung \\ tegar.andito@machung.ac.id
}

\begin{abstract}
Andhe Andhe Lumut is a folktale that derived from many versions of Panji tales. Andhe Andhe Lumut is the popular one amongst Indonesian, especially Javanese cultures. In popular culture, there are many works in various media that derived from Andhe Andhe Lumut story. Originally, as one of Panji tales, Andhe Andhe Lumut background story takes place at Kediri Kingdom era, but most of visual works like comics, picture story books, animations, drama costumes, etc use far more modern era style of traditional Javanese culture. Beside of that, from original text, Andhe Andhe Lumut folktale is designed for adult audiences, however most Indonesians have identified that folktale is a bedtime story for children. That's why people can't find visual works from Andhe Andhe Lumut story for adult audiences. As mentioned before, Panji tales have many versions. They are also already popular since Majapahit era. This is proven by carvings about some scene from Panji tales at Penataran Temple Complex which most of stuctures are built at Majapahit era. Panji tales themselves are semi fictional stories. Prince Panji or Inu Kertapati is inspired from King Kameswara II, seventh king of Kingdom of Kediri, and Princess Candra Kirana is inspired from Queen Kirana from Jenggala, but in Panji tales, their origins are opposite. Panji is from Jenggala and Candra Kirana is from Kediri. Ancient Javanese temple carvings could shows anything, but always showed environmental situations when the carvers live."Teras Pendopo" building, where Panji tales carvings are located, was built at Majapahit era, when King Hayam Wuruk reigned. It is about 100 years after fall of Kediri, so the carvings are the closest visualization of Kingdom of Kediri daily life.
\end{abstract}

Visualization of Andhe Andhe Lumut folktale based on original text and Panji tales characters at Penataran Temple Complex has never done before. Panji tales at Penataran Temple itself does not tell Andhe Andhe Lumut version of Panji. This comic design, if done properly can gives a new point of view about Andhe Andhe Lumut and can be the first comic of Andhe Andhe Lumut for adult audience with some historical accuracy.

Keywords: Penataran Temple, Panji, Folktale, Andhe Andhe Lumut, Comic.

\section{PENDAHULUAN}

Kisah Ande Ande Lumut merupakan salah satu cerita rakyat yang populer bagi masyarakat Indonesia, terutama bagi yang memiliki latar belakang budaya Jawa. Kisah yang merupakan turunan Kisah Panji ini awalnya disebarkan secara lisan di lingkungan masyarakat Jawa. Kisah Ande Ande Lumut sendiri banyak diadaptasi dalam bentuk sandiwara dan tak asing pula diceritakan sebagai dongeng sebelum tidur bagi anakanak. Pada masa kini, cerita ini banyak disadur ke dalam budaya populer berupa berbagai macam versi cerita bergambar dan video animasi. Cerita ini bersetting di masa Kerajaan Kediri, namun visualisasinya dalam budaya populer hampir selalu menampilkan keadaan pada masa jauh setelahnya.

Di kalangan masyarakat Indonesia, cerita rakyat sudah terlanjur identik dengan 
'dongeng sebelum tidur' yang target audiensnya pasti anak-anak, padahal tidak semua cerita rakyat cocok untuk didengar audiens anak-anak. Cerita Ande Ande Lumut sendiri awalnya bukan cerita anak-anak karena terdapat beberapa bagian yang menceritakan Kleting Abang, Ijo, dan Biru harus rela dicium oleh tokoh Yuyu Kangkang. Terdapat beberapa versi mengenai apa dan siapa sebenarnya Yuyu Kangkang ini. Beberapa versi menyebutkan bahwa Yuyu Kangkang ini adalah seorang tukang perahu, seekor kepiting raksasa atau siluman kepiting, dan dalam versi lain ciuman Yuyu Kangkang disamarkan dengan sekedar mencubit dengan sapitnya.

Panji diketahui ada dalam tradisi tutur lisan rakyat, dan kisah pengembaraan Panji untuk mencari Candrakirana menjadi sumber inspirasi berbagai dongeng rakyat. Dongeng tentang Timun Emas, Keong Mas, Bango Tong-tong, Lomaran, Ande-ande Lumut, enthit, danlainnya merupakan kisah pengembaranPanji yang sedang "namur laku"(Manuaba, Setijowati, dan Karyanto 2013, 62). Berdasarkan kutipan Lydia Kieven dari Poerbatjaraka, tokoh Panji dan Candrakirana merupakan penggambaran dari Raja Kameswara (raja VII Kerajaan Kediri yang berkuasa sekitar tahun 1180-1190) dan permaisurinya Kirana $(2014,38)$. Dongeng Ande Ande Lumut walaupun tersebar secara lisan di kalangan masyarakat Jawa, ternyata juga tercatat dalam naskah tertulis. Paling tidak ada dua naskah Ande Ande Lumut, pertama merupakan koleksi Fakultas Sastra Universitas Indonesia Jakarta, dan berdasarkan daftar yang disusun oleh Darusuprapta, terdapat satu naskah lagi yang menjadi koleksi Museum Sanabudaya Yogyakarta (Baried et al. 1987, 206,210).

Cerita Panji populer sejak masa Kerajaan Majapahit. Salah satu bukti popularitasnya adalah terpahatnya visualisasi cerita ini dalam relief sejumlah candi era Majapahit. Menurut catatan Lydia Kieven, sejumlah candi tersebut antara lain Candi Penataran, Situs-situs candi di Gunung Penanggungan, Candi Rimbi, Candi Mirigambar, Relief Gambyok, dan arca Panji dari Grogol (Kieven 2014, 147-56). Dari beberapa candi tersebut, Candi Penataranlah paling banyak memuat cuplikan Kisah Panji. Relief mengenai Kisah Panji ini dapat ditemukan pada bangunan Teras Pendopo. Bangunan ini sendiri dibangun pada $1375 \mathrm{M}$, yakni pada masa pemerintahan Raja Hayam Wuruk (Kieven 2014, 191).

Relief pada candi menampilkan elemenelemen visual yang ada ketika candi itu dibangun. Relief candi sendiri sudah dapat digolongkan komik karena gambar-gambar yang ada tersusun secara berurutan dan membentuk cerita (Soedarso 2015, 498). Walaupun sudah berupa komik, relief candi harus dibaca dengan cara yang tidak biasa dilakukan orang dewasa pada zaman modern ini. Menurut Tabrani, relief candi harus dibaca dengan metode ruang waktu datar (RWD) untuk dapat dipahami isinya (Tabrani 2009, 5). Bahasa visual RWD ini akrab dibaca oleh anak-anak (Tabrani 2001, 12-13), namun menjadi tidak mudah dibaca bagi orang dewasa modern karena terbiasa membaca bahasa visual dengan metode Naturalis-Perspektif-Momen opname atau NPM.

Penceritaan kembali kisah Ande Ande Lumut dalam bentuk cerita bergambar, 
komik, dan animasi sejauh ini umumnya dibuat untuk konsumsi anak-anak, padahal kisah aslinya bukanlah kisah untuk audiens anak-anak. Dari segi visualisasi sendiri, penampilan setting, busana karakter, dan bangunan umumnya berdasarkan produk budaya tradisional Jawa pada masa yang jauh lebih modern (misal: Putri Candrakirana digambarkan mengenakan kebaya atau pangeran Panji Asmarabangun/Inu Kertapati mengenakan busana seperti sultan-sultan Jawa). Sangat jarang pada masa kini cerita Ande Ande Lumut diceritakan kembali dalam format untuk audiens yang lebih dewasa. Tidak pernah pula kisah Ande Ande Lumut ini dalam format modern seperti animasi, cerita bergambar, dan komik divisualisasikan dengan gaya penampilan yang mendekati zaman ketika setting cerita ini terjadi.

Visualisasi kisah Ande Ande Lumut berdasarkan tokoh-tokoh Kisah Panji pada relief candi ke dalam komik modern dengan narasi untuk audiens dewasa belum pernah dilakukan sehingga akan menjadi hal baru jika itu dilakukan. Kisah Panji pada Candi Penataran sendiri tidak menceritakan kisah Ande Ande Lumut. Walaupun begitu reliefrelief yang ada dapat diaplikasikan kembali ke dalam cerita yang berbeda seperti kisah Ande Ande Lumut ini karena memiliki tokohtokoh utama yang sama. Perancangan komik yang akan dilakukan juga akan akan memindahkan penampakan-penampakan pada relief candi dari bahasa rupa RWD ke dalam pemaparan cerita dengan bahasa visual NPM yang mudah dipahami oleh orang dewasa kebanyakan pada zaman modern ini.

\section{Kisah Andhe Andhe Lumut dalam Budaya} Populer

Kisah Panji pada dasarnya menceritakan kisah cinta Pangeran Panji Asmarabangun atau Raden Inu Kertapati dengan Putri Candrakirana atau Dewi Sekartaji mulai dari bertemu, menikah, terpisah karena konflik kerajaan, pencarian kembali dan akhirnya bertemu kembali. Sebagian cerita rakyat yang merupakan turunan Kisah Panji menceritakan berbagai versi bagaimana Panji dan Candrakirana bertemu kembali dan Kisah Ande Ande Lumut merupakan salah satunya. Kisah Ande Ande Lumut dimulai setelah Panji dan Candrakirana berpisah.

Di Indonesia, cerita rakyat ini telah diadaptasi dalam berbagai macam media. Terdapat gambar umbul, cerita bergambar, animasi, sandiwara, dan lagu pop daerah. Berikut ini adalah beberapa contoh pengadaptasian Kisah Ande Ande Lumut dalam berbagai media.

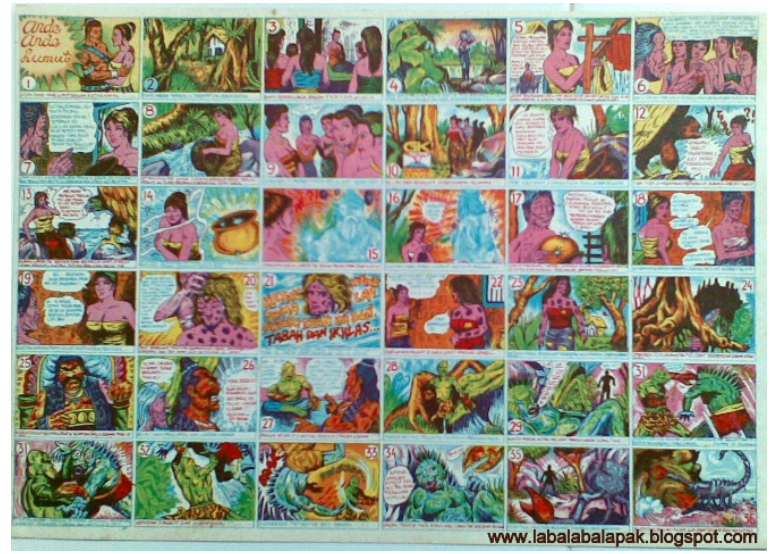

Gambar 1 Gambar umbul Ande Ande Lumut (Joel n.d.) 


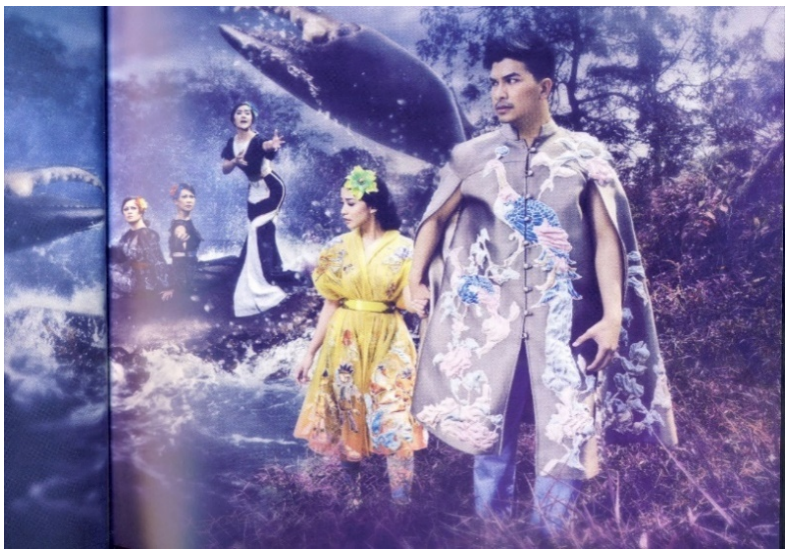

Gambar 2 Ande Ande Lumut karya Rio Motret (Wibowo 2016, 8-9)

\section{Komik dan Cergam Tentang Relief Candi yang Pernah Ada}

Sudah pernah ada komik dan cerita bergambar modern yang dirancang berdasarkan relief candi. Saat tulisan ini dibuat, baru Candi Borobudurlah yang reliefnya diambil sebagai materi komik dan cerita bergambar. Terdapat tiga buku komik dan cerita bergambar berdasarkan candi Borobudur, yang pertama adalah Borobudur Pusaka Abadi Nan Jaya yang ditulis oleh Handaka Vijjananda, Jataka dan Karmawibangga I yang artistiknya disusun oleh Tim Welut. Dari gaya karakter yang digunakan, Borobudur Pusaka Abadi Nan Jaya dirancang untuk anak-anak. Hal ini dapat dilihat dari karakter-karakter yang dibuat dengan deformasi kepala yang lebih besar dan wajah yang cenderung dibuat chibi, walau begitu, bahasa visual yang digunakan menggunakan NPM. Lain halnya dengan Jataka dan Karmawibhangga I, cergam ini lebih ketat dalam mengambil obyek, penampilan, dan pose karakter. Cergam ini dibuat untuk menggambarkan kembali relief Candi Borobudur dalam ilustrasi di atas kertas dengan warna serta kaidah-kaidah anatomi dan perspektif yang lebih realis.
Selain prinsip dan elemen tersebut, cergam ini dibuat sebisa mungkin sama dengan relief aslinya termasuk cara membacanya yakni dengan bahasa visual RWD. Hal ini disebabkan karena cergam ini lebih menekankan akurasi dan lebih ditujukan kepada audiens yang juga mempelajari sejarah Indonesia.

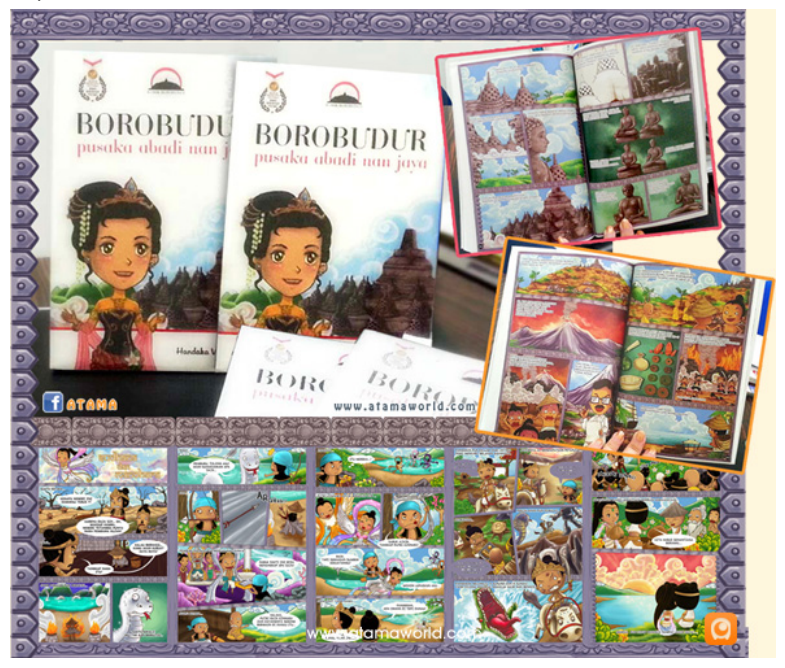

Gambar 3 Preview komik Borobudur Pusaka Abadi nan Jaya (Nirvana Gallery 2015)

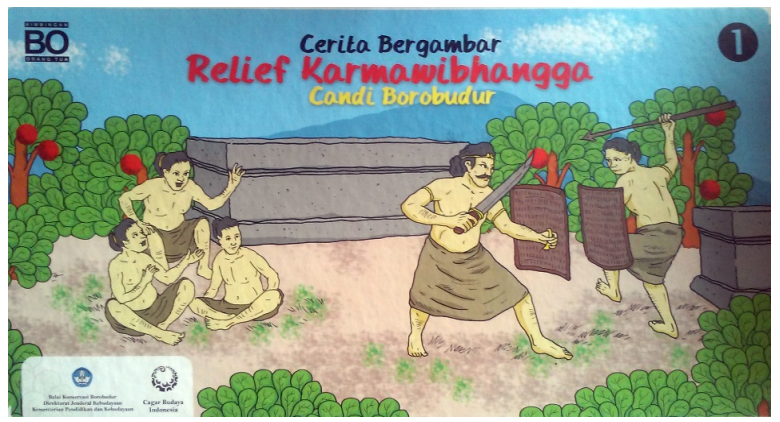

Gambar 4 Sampul buku cergam Karmawibhangga (Balai Konservasi Borobudur 2016) 


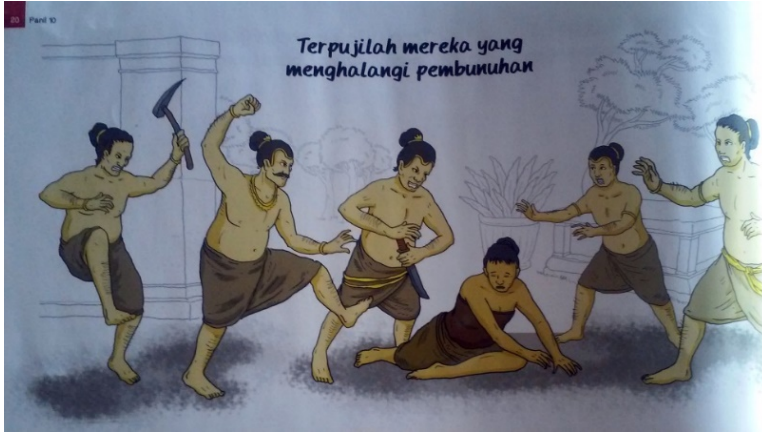

Gambar 5 Adegan pembunuhan dalam Cergam Karmawibhangga 1 (Balai Konservasi Borobudur 2016, 20)

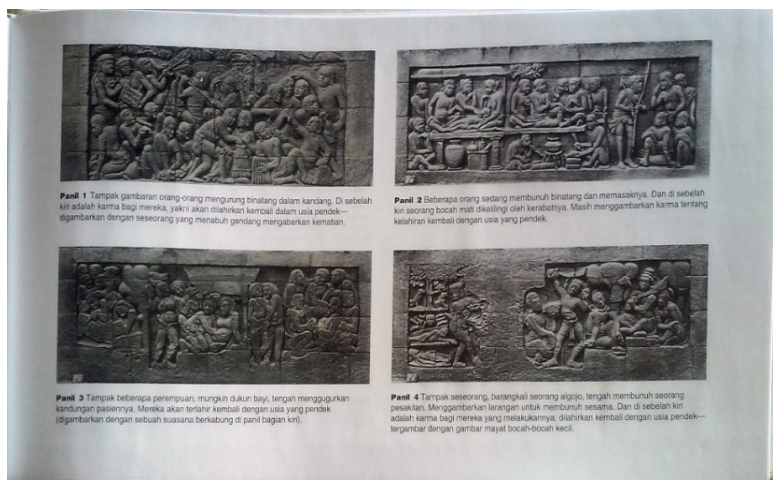

gambar 1lampiran pada Cergam Karmawibhangga I, relief di kiri bawah merupakan relief pada gambar yang dimaksud pada dua gambar sebelumnya (Balai Konservasi Borobudur 2016)

\section{Naskah Cerita Andhe Andhe Lumut}

Naskah yang digunakan dalam perancangan komik ini adalah naskah Cariyos Andhe Andhe Lumut koleksi Perpustakaan Museum Negeri Sonobudoyo Yogyakarta. Naskah cerita Ande Ande Lumut yang dikoleksi Museum Sonobudoyo Yogyakarta adalah naskah tulisan tangan berjudul Cariyos Andhe Andhe Lumut yang ditulis dalam tulisan tangan beraksara Jawa oleh M Sinoe Mandisoera pada tahun 1930. Naskah ini telah ditranskripsi ke aksara Latin oleh Karsemiyatun (1998).

Setting cerita berada di wilayah Jawa Timur pada masa kerajaan Kediri dan
Jenggala di mana Kediri dipimpin oleh Prabu Lembu Peteng dan Jenggala yang dipimpin oleh Prabu Lembuamiluhur yan didampingi oleh permaisuri yang tidak disebut namanya. Tokoh istana lain adalah seorang patih dari Kediri yang tak disebut namanya yang tinggal bersama dengan kedua tokoh utama di Jenggala. Tokoh utama dalam cerita ini adalah Panji Kudawenengpati atau Raden Putra yang menyamar menjadi Andhe Andhe Lumut dan Dewi Sekartaji atau Dewi Candra Kirana yang menyamar menjadi Kleting Kuning. Terdapat tokoh pembantu yang berperan sebagai punakawan bagi Raden Putra yakni Jodheh (Jurudeh) dan Sonta (Prasanta). Dalam petualangannya, Raden Putra bertemu Mbok Randha Dhadhapan sedangkan Dewi Candra Kirana bertemu dengan Mbok Randha Karangwulusan. Terdapat tokoh dewa yakni Sang Hyang Narada yang di tengah cerita juga menyamar sebagai Bango Thonthong. Terdapat pula tokoh dewa lain yakni Dewa Siwa atau Sang Hyang Pramesti Guru namun dalam cerita ini hanya disebut namanya saja. Tokoh-tokoh antagonis dalam cerita ini adalah anak perempuan Mbok Randha Karangwulusan yakni (dari yang paling tua) Kleting Biru, Kleting Abang, dan Kleting Ijo yang mempunyai nama lain Kleting Wungu(Moendisoera 1930, 37). Tokoh antagonis lain adalah Yuyu Kangkang yang sesungguhnya adalah seorang resi yang sedang menjalani hukuman akibat suatu kesalahan di masa lalu.

Dalam cerita disebut pula beberapa macam tanaman. Tanaman tersebut adalah ketela, gembili, randu (dari wanarandu), dan tanaman genjer (gundha weweyan). Beberapa makanan juga disebut seperti nasi, sayur- 
sayuran, ketela, umbi gembili, dan raja brana (sekelompok makanan mewah para raja). Raja brana hanya disebutkan secara umum saja di sini dan tidak disebutkan tiap-tiap makanan yang dikategorikan sebagai raja brana.

\section{Rekonstruksi Wajah Tokoh-tokoh Panji di Candi Penataran dan Percobaan Penggambaran Lingkungan Masa Kediri}

Tokoh Panji diidentifikasi dari sosok pria bertopi tekes berdasarkan identifikasi dari Lydia Kieven. Lydia Kieven tidak menyebut relief mana yang menampilkan tokoh Dewi Candra Kirana, namun dari identifikasi tokoh Panji, tokoh Dewi Candra Kirana diidentifikasi dari sosok perempuan muda yang bermesraan dengan Panji. Menurut Regina Yofani (2010) tanaman yang digambar di relief Candi Penataran adalah Pinang, Pandan, Asoka, Teratai, Kelapa, Aren, Beringin, Mangga, Kamboja, Glodokan, Tanjung, Sukun, dan Bakung.

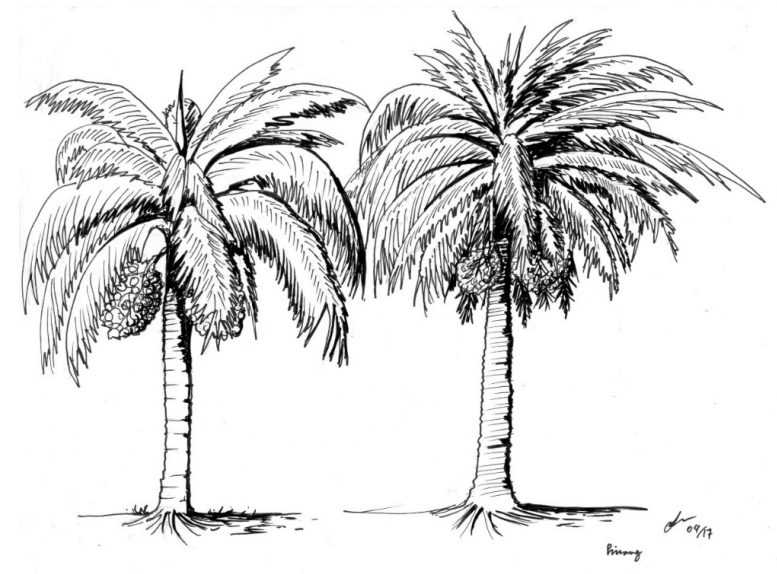

Gambar 6 uji coba penggambaran pohon pinang

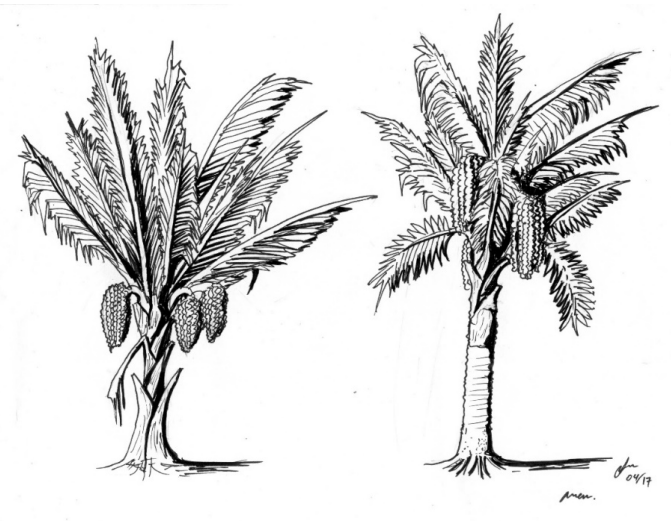

Gambar 7 Uji coba penggambaran pohon aren

Dari pengamatan yang telah dilakukan, hampir semua relief wajah kekasih Panji pada Teras Pendopo Candi Penataran telah rusak maupun telah aus. Satu-satunya wajah yang relatif utuh adalah relief kekasih Panji pada panel 51, Kisah Burung Kakaktua. Wajah kekasih Panji ini sudah rusak separuh, namun bagian yang masih utuh kondisinya relatif baik. Mata, alis, dan bibir masih dapat dilihat, sehingga ekspresi wajah juga masih dapat dikenali. Untuk tokoh Panji sendiri, terdapat banyak relief dengan wajah yang tidak rusak dan masih dapat dikenali. Wajah Panji dengan kondisi terbaik adalah pada relief 43 , Kisah Prosesi. 


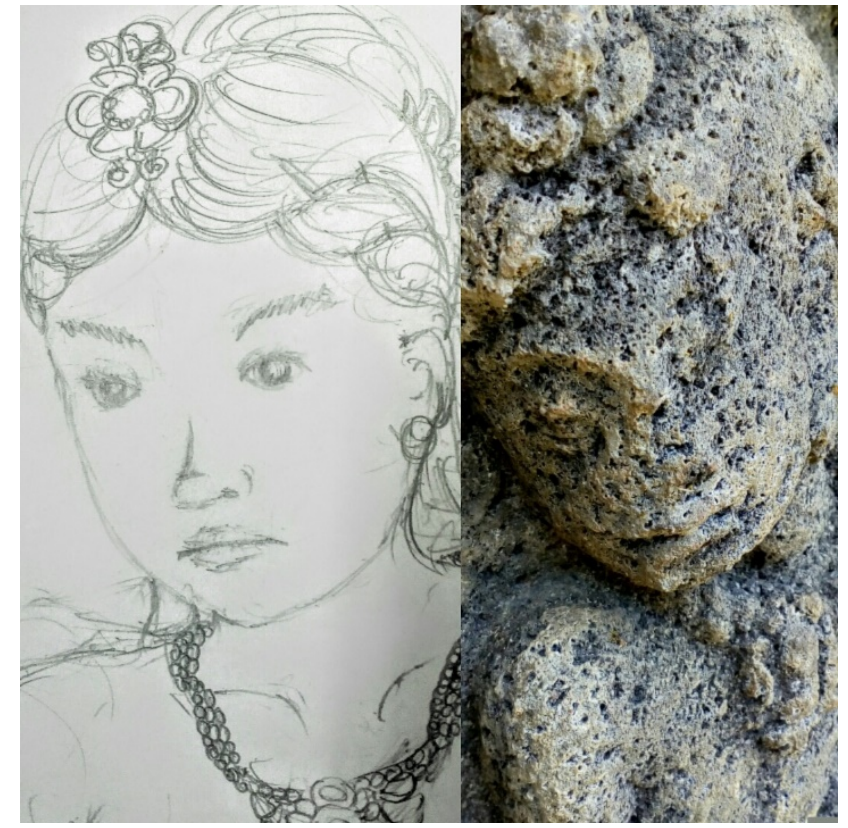

Gambar 8 Perbandingan wajah rekonstruksi dengan wajah pada panel 51

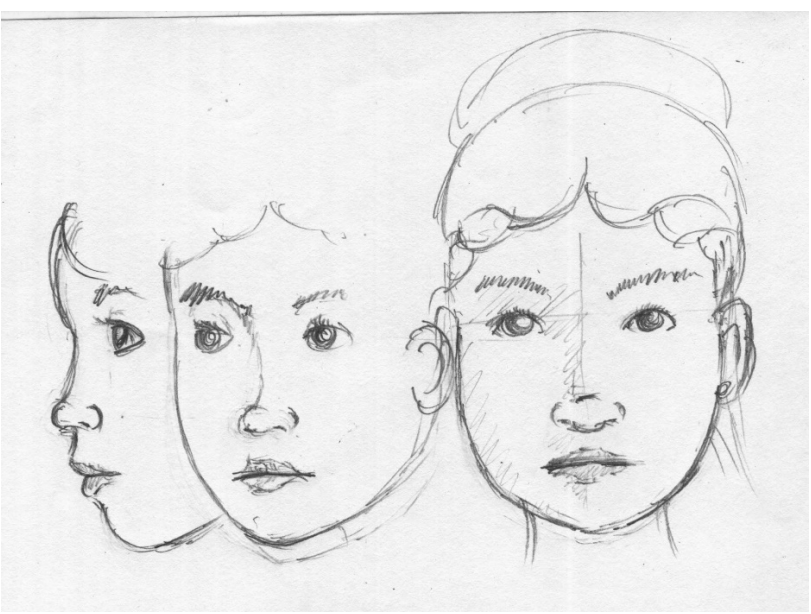

Gambar 9 Pengembangan wajah Candra Kirana lebih lanjut

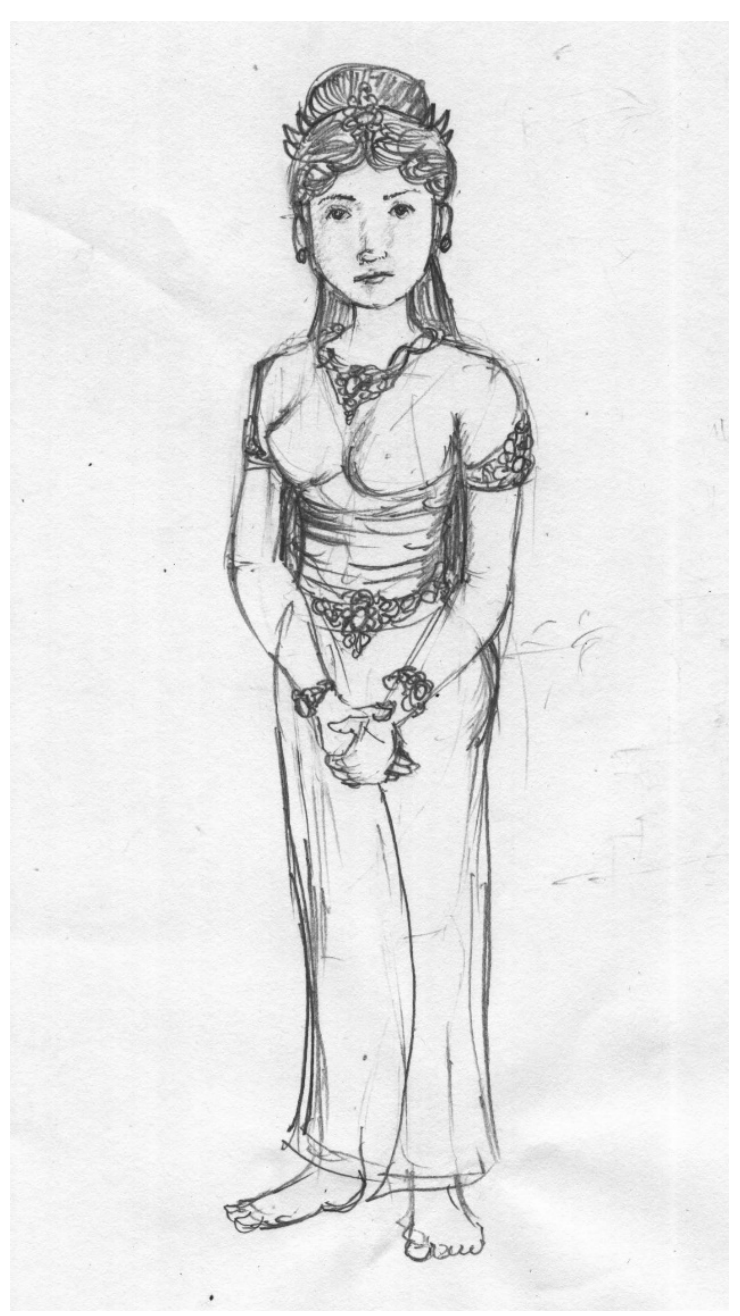

Gambar 10 Uji coba penggambaran seluruh tubuh Putri Candra Kirana

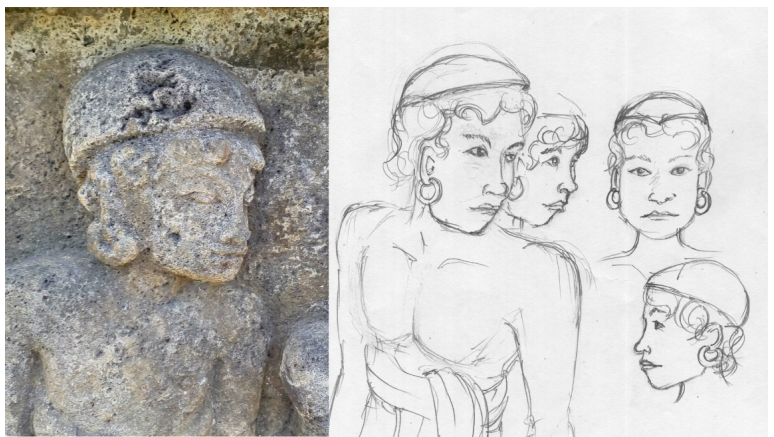

Gambar 11 Perbandingan relief candi Teras Pendopo panel 43 dengan hasil rekonstruksi

Jodheh memiliki nama lain yakni Dhoyok, Jaradeh, atau Tembem (Sabdacarakatama 2008, 192). Tokoh ini merupakan punakawan sebagaimana 
layaknya Semar, Gareng, Petruk, dan Bagong pada Kisah Mahabharata versi wayang kulit Jawa. Jodheh, pada kisah-kisah Panji yang lain digambarkan bertubuh gemuk sehingga mirip tokoh Semar pada wayang kulit Mahabharata.

Di bangunan Teras Pendopo Candi Penataran memang ditampilkan beberapa relief tokoh-tokoh yang digambarkan sebagai punakawan, namun tak diketahui siapa nama tokoh punakawan pada relief bangunan tersebut. Walaupun begitu, jika melihat ciriciri fisik yang biasa ditampilkan dan dideskripsikan di kisah-kisah Panji yang lain, maka yang paling mendekati adalah tokoh punakawan pada panel 54, Kisah dengan Pemain Reyong.

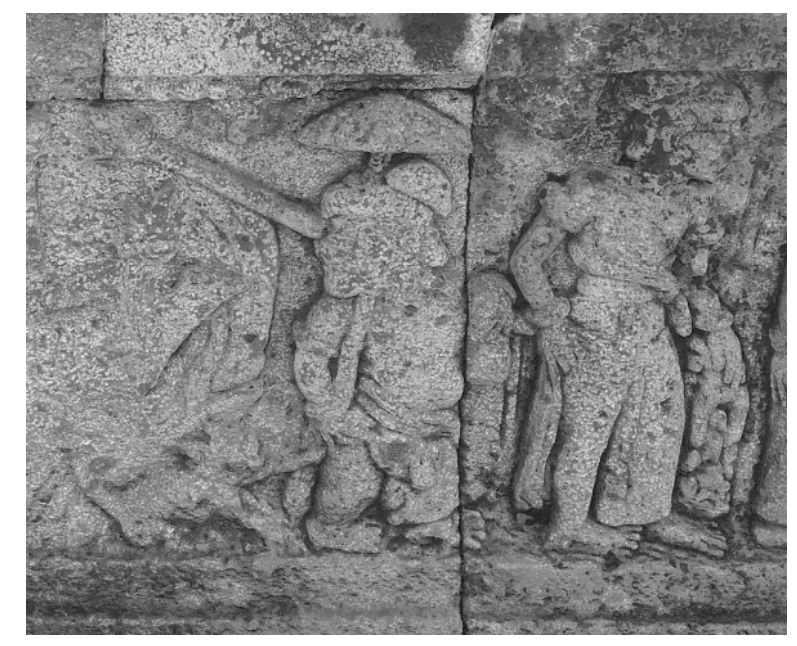

Gambar 12 Tokoh yang mirip dengan deskripsi fisik Jodheh (sumber: Tegar Andito)

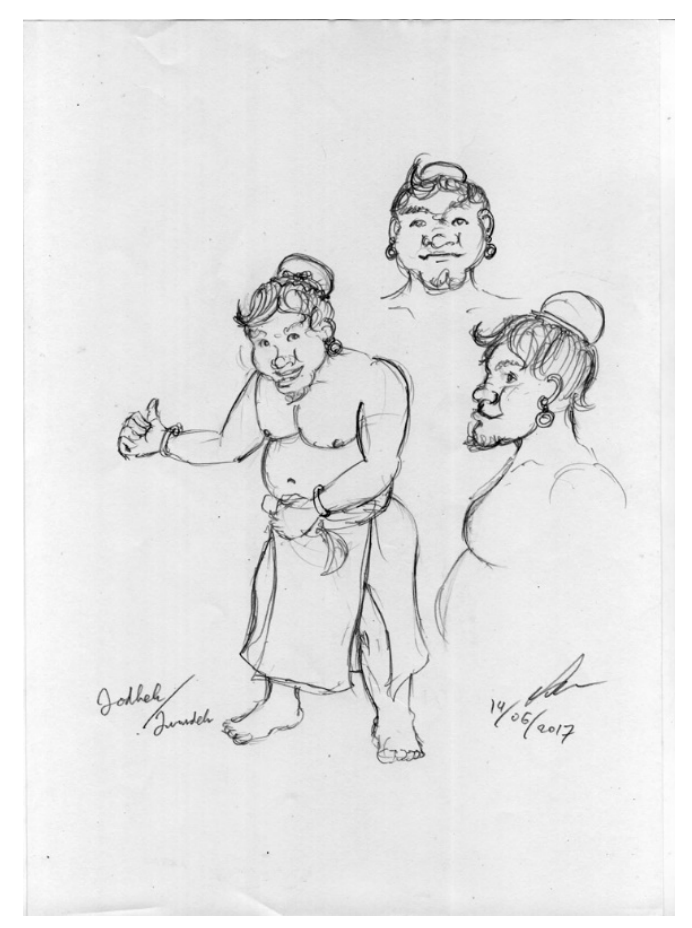

Gambar 13 Rekonstruksi fisik tokoh Jodheh berdasarkan relief 54, Kisah dengan Pemain Reyong

$\begin{array}{llrr}\text { Sonta } & \text { memiliki nama lain yakni } \\ \text { Penthul, } & \text { Bancak, } & \text { atau } & \text { Prasonto }\end{array}$ (Sabdacarakatama 2008, 192). Seperti halnya Jodheh, Sonta juga merupakan punakawan. Tokoh ini digambarkan bertubuh lebih kurus dan lebih kecil dibandingkan Jodheh. Kadang-kadang juga disamakan dengan Gareng dari kisah Mahabharata versi wayang kulit.

Di Bangunan Teras Pendopo Candi Penataran, tokoh yang mirip dengan derskripsi fisik yang telah disebutkan ini muncul beberapa kali. Contohnya pada relief 46, Kisah Prosesi atau relief panel 47-49, Kisah Burung Kakaktua. Agar lebih menarik, rekonstruksi tokoh ini sedikit dimiripkan dengan tokoh Merdah pada wayang kulit versi Bali. 


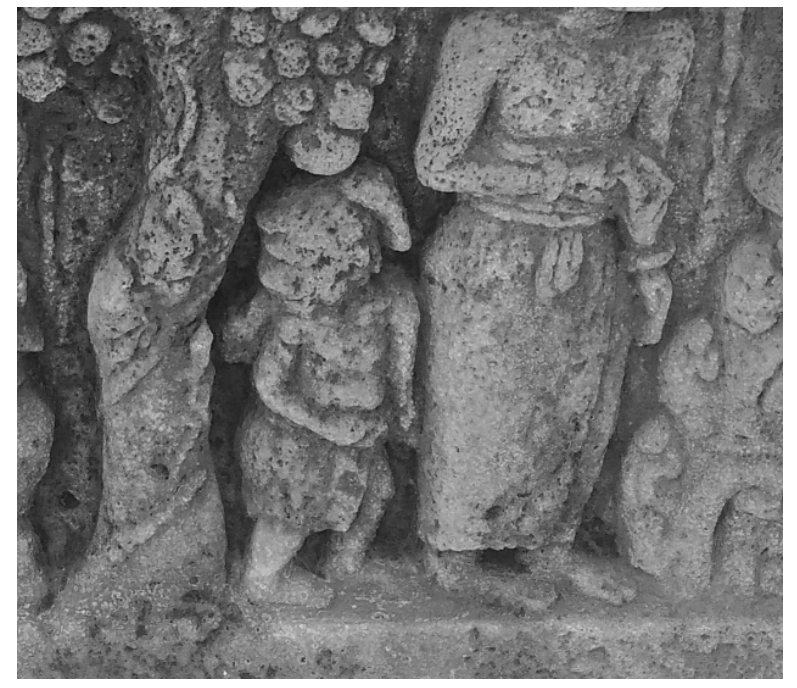

Gambar 14 Tokoh yang diduga Sonta dari panel 46, Kisah Prosesi

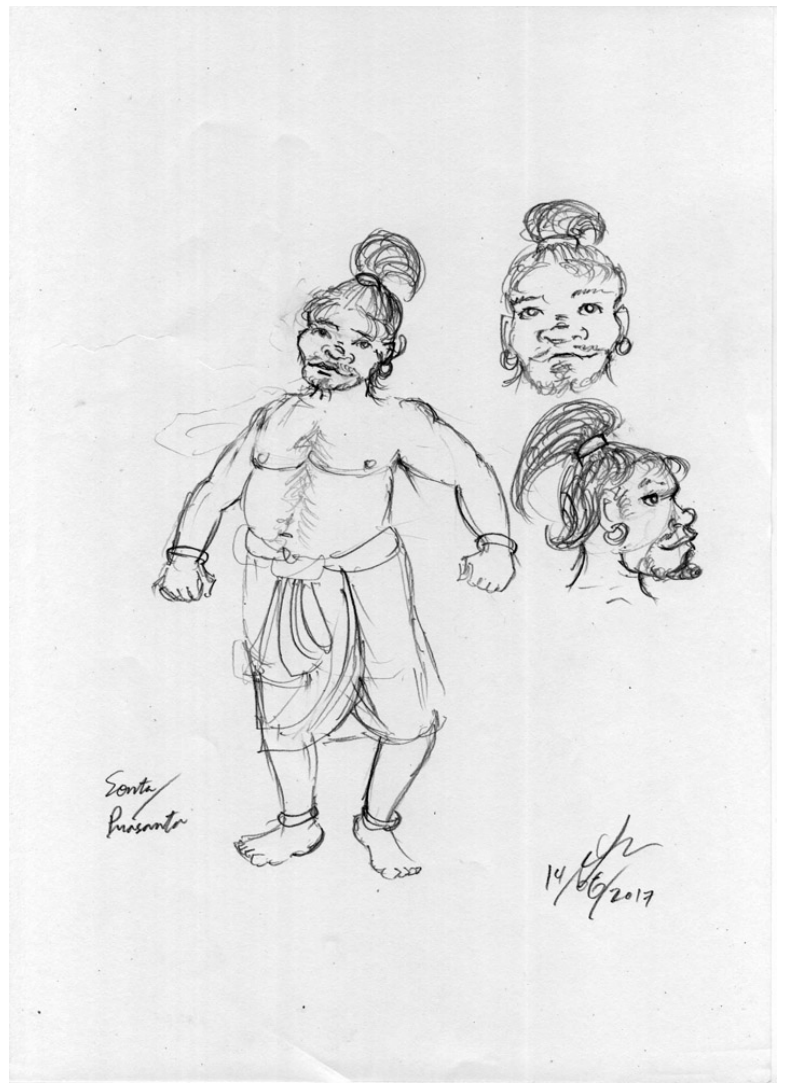

Gambar 15 Hasil rekonstruksi fisik dan wajah tokoh Sonta

Tidak semua tokoh yang diceritakan dalam naskah Cariyos Andhe Andhe Lumut juga dipahatkan dalam relief Teras Pendopo
Candi Penataran. Untuk mengatasi hal ini, maka dikaranglah gambar tokoh-tokoh dalam naskah. Walaupun tokoh-tokoh yang tak muncul di relief Teras Pendopo Candi Penataran ini dikarang, namun visualnya tetap dirancang agar dapat bersumber pada relief-relief yang ada di dalam Kompleks Candi Penataran namun menampilkan sifat karakter yang diceritakan dalam naskah, atau paling tidak tokoh yang bersangkutan mengenakan atribut-atribut masa Kerajaan Hindu-Buddha terutama sekitar masa Kerajaan Kediri.

Naskah Andhe-Andhe Lumut bersetting di sekitar daerah kekuasaan Kerajaan Jenggala dan Kediri. Pemandangan latar belakang diuji coba pula penggambarannya dengan siluet pegunungan yang ada agar dapat dikenali di mana adegan cerita terjadi. Untuk dapat lebih kuat membedakan di mana suatu adegan terjadi, maka unsur arsitektur pada daerah Jenggala dan Kediri juga dibedakan. Di dalam komik ini kerajaan Jenggala yang beribukota di Kahuripan digambarkan mendapatkan warisan peninggalan Kerajaan Kahuripan masa Airlangga dan Kerajaan Medang pada masa sebelumnya, maka di lingkungan Jenggala lebih banyak ditampilkan bangunanbangunan dan relief bergaya Jawa Tengahan walaupun juga terdapat bangunan bergaya Jawa Timuran. Untuk menggambarkan Kediri maka lebih banyak ditampilkan bangunan-bangunan klasik bergaya candi Jawa Timur. 


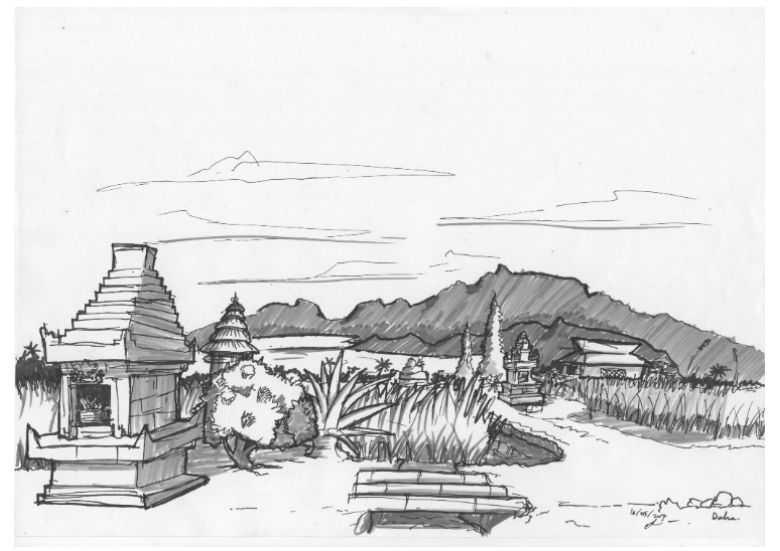

Gambar 16 Uji coba latar belakang daerah Daha/Kediri dengan siluet Gunung Wilis

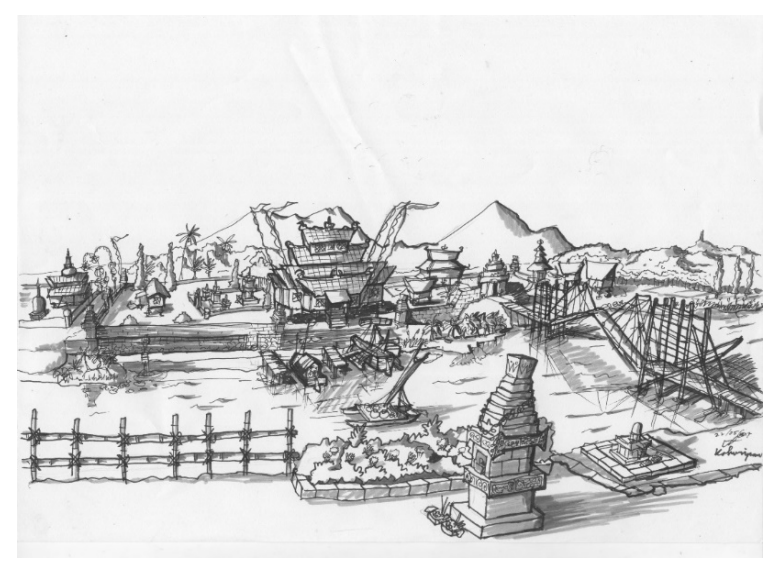

Gambar 17 Uji coba latar belakang ibukota Jenggala (Kahuripan) dengan menampilkan siluet Gunung Arjuna dan Penanggungan, serta menyertakan sungai Porong

\section{Komik Andhe Andhe Lumut}

Tidak semua hal yang ada di naskah Cariyos Andhe Andhe Lumut juga ditampilkan di relief Candi Penataran sehingga diperlukan sumber-sumber lain untuk dapat diterapkan sebagai komik. Terinspirasi dari cergam Karmawibhangga 1, perancangan komik ini juga mencoba menekankan pula akurasi sejarah walaupun tidak seketat cergam Karmawibhangga 1. Naskah Cariyos Andhe Andhe Lumut ditulis pada abad XX yang bisa jadi merupakan catatan dari cerita lisan. Terdapat anakronisme pada jalan cerita Andhe Andhe
Lumut di naskah ini sehingga cerita yang akan dieksekusi di komik harus sedikit diubah. Anakronisme yang ada ialahpenyebutan nama Singosari padahal setting cerita berada di masa Kediri, kemudian penyebutan tanaman ketela dan genjer (gundha weweyan) di mana tanaman yang berasal dari Amerika tersebut belum dikenal di Jawa pada masa itu.

Sebagai contoh dalam hal ini adalah pembahasan Komik Andhe Andhe Lumut pada halaman 3, 8, dan 9.Pada halaman 3 panel bagian atas ditampilkan situasi lingkungan di Ibukota Kerajaan Kediri. Beberapa pohon palem-paleman ditampilkan dengan pohon pinang ditampilkan lebih banyak daripada pohon kelapa. Pohon pinang ditampilkan lebih banyak karena di dalam relief Candi Penataran lebih banyak muncul pohon pinang dibandingkan pohon palma yang lain sehingga dapat diasumsikan pada masa itu populasi pohon pinang lebih banyak dibandingkan pohon-pohon dari suku Arecaceae yang lain. Di panel yang sama ditampilkan pula Sungai Brantas dengan latar belakang Gunung Wilis agar menunjukkan bahwa di tempat ini adalah wilayah Kediri. Ditampilkan pula candi dengan tata letak Candi Hindu dengan gaya Jawa Timuran serta stupa untuk menunjukkan setting waktu masa kerajaan Hindu-Buddha. Gerbang istana Kediri yang menghadap Sungai Brantas digambarkan mirip dengan gerbang Ratu Boko. Adegan tari di panel bawah menggunakan pose yang sama dengan adegan tari di salah satu relief Candi Borobudur. Di latar belakang panel bawah nampak Prabu Lembu Peteng dengan mahkota yang meniru mahkota Sri Rama pada relief Kisah Ramayana pada Candi Induk Penataran. 


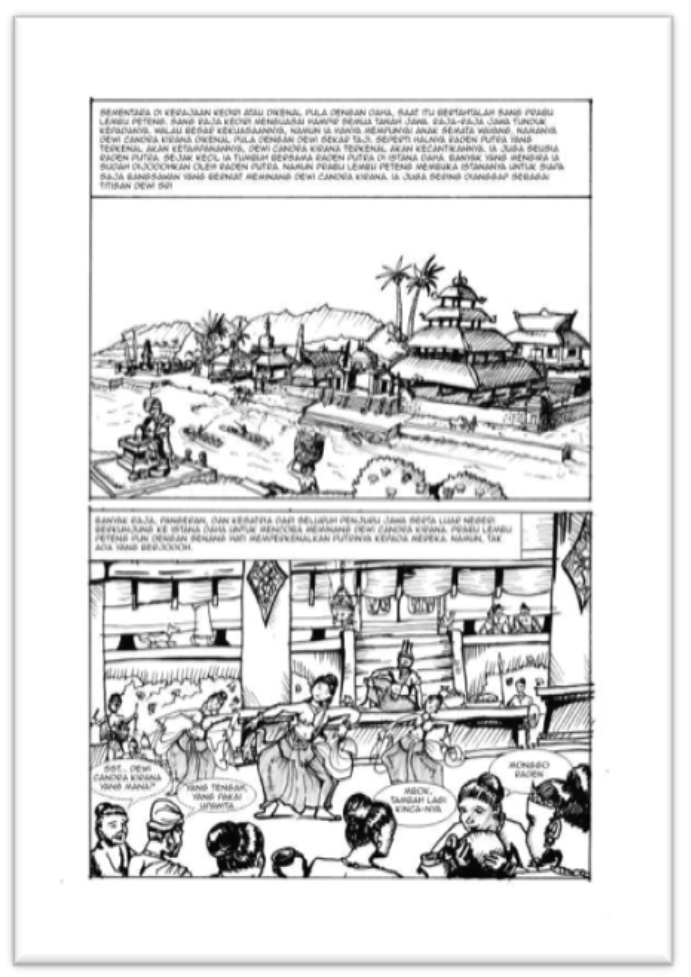

Gambar 18 Halaman 3 Komik Andhe Andhe Lumut

Adegan-adegan pada halaman 8 sebagian besar mirip dengan yang tergambar di relief Candi Penataran. Pada panel atas semua rakyat jelata menyembah raja yang sedang lewat. Beberapa pemuka agama dan bangsawan menyembah dalam posisi berdiri untuk menunjukkan kedudukan mereka yang lebih tinggi dari rakyat jelata. Pada panel tengah sebelah kanan ditampilkan seperangkat bahan-bahan mengunyah sirih namun tanpa tembakau karena di Jawa pada masa itu tembakau masih belum dikenal. Di dalam Candi Penataran di sejumlah adegan nampak beberapa pelayan membawa tempat sirih sehingga dapat disimpulkan bahwa mengunyah sirih adalah hal sehari-hari yang biasa dilakukan. Di panel tengah kiri dan bawah kiri terdapat dua orang pengawal berdiri di belakang raja. Pakaian dan gaya rambut pengawal ini dibuat meniru dwarapala namun dalam wujud manusia biasa. Perhiasan yang dikenakan Prabu Lembuamiluhur meniru artefak mahkota masa Kerajaan Kahuripan dari foto Museum Online Wilwatikta, koleksi foto Deddy Endarto (2011). Hiasan dada Garudheya era Kediri koleksi Museum Mpu Tantular, dan kelat bahu era Mataram Kuno koleksi Yale Museum Amerika Serikat.

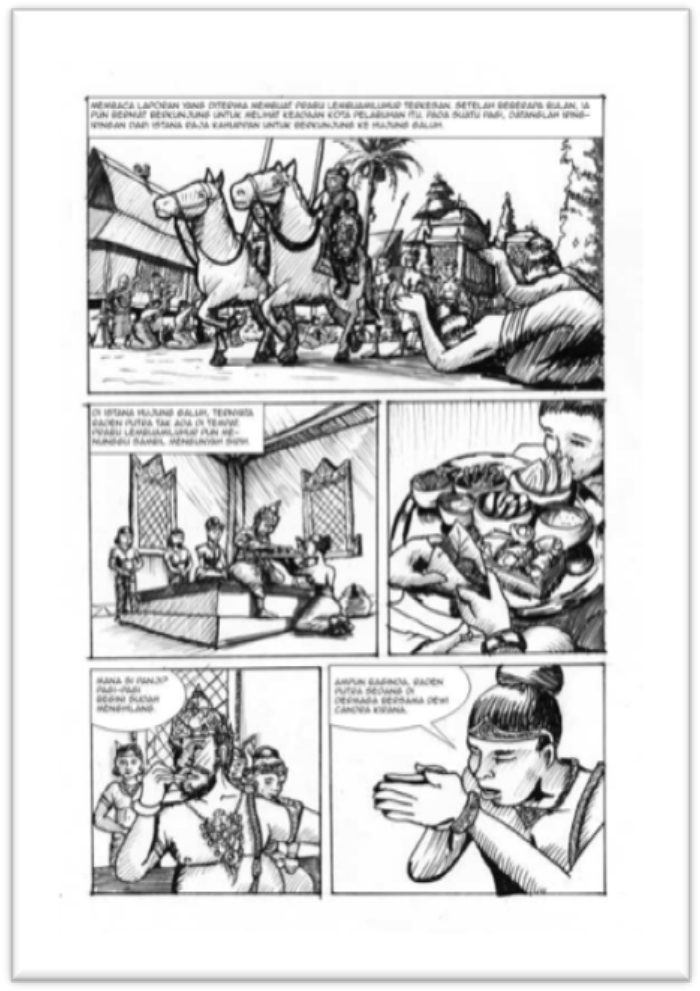

Gambar 19 Halaman 8 Komik Andhe Andhe Lumut

Pada halaman 9 panel tengah dan bawah ditampilkan adegan yang berlokasi di pelabuhan Hujung Galuh. Jodheh, Sonta, dan Candra Kirana ditampilkan sesuai dengan rekonstruksi yang ada, namun tokoh Panji ditampilkan lebih detil dibandingkan hasil rekonstruksi. Perhiasan dan detil-detil lain diambil dari penampilan arca Panji dari Candi Selokelir. Pada halaman ini terdapat adegan Panji sedang berniaga dengan seseorang berpenampilan Timur Tengah. 
Adegan ini dirancang untuk menunjukkan bahwa Hujung Galuh merupakan kota pelabuhan yang ramai dikunjungi pedagang dari berbagai pelosok wilayah.

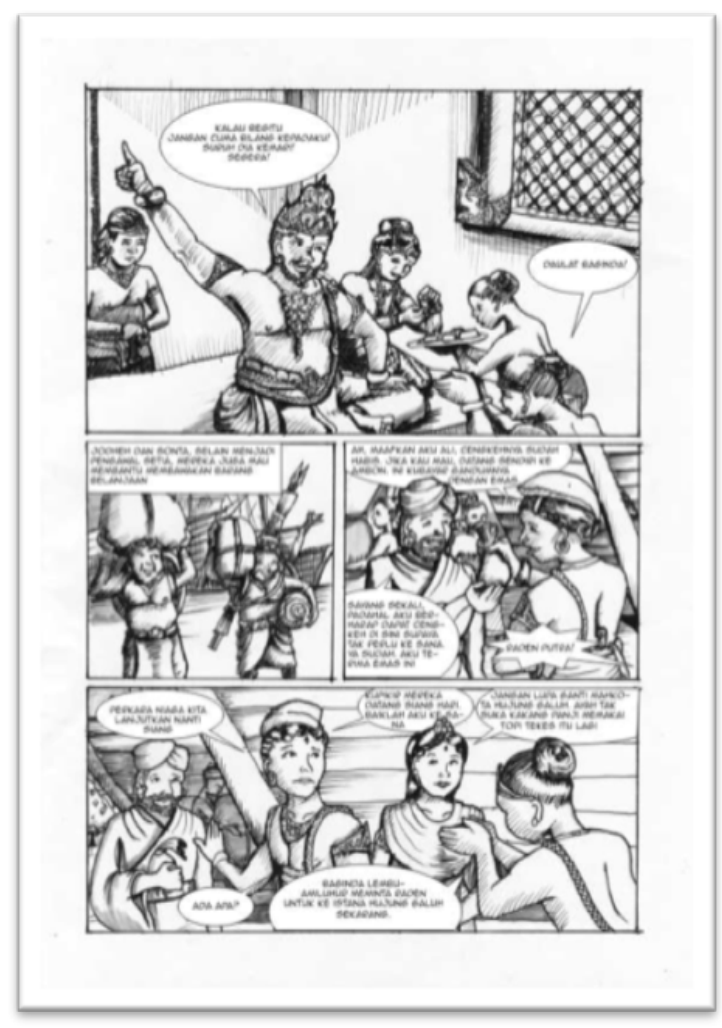

Gambar 20 Halaman 9 Komik Andhe Andhe Lumut

\section{KESIMPULAN}

Perancangan komik Andhe Andhe Lumut ini tidak dapat terlalu ketat mengikuti naskah Cariyos Andhe Andhe Lumut dan juga murni menggunakan relief Candi Penataran. Penambahan sedikit unsur akurasi sejarah juga akhirnya mengharuskan terjadinya perubahan sedikit bagian dari cerita asli untuk menghindari anakronisme. Beberapa tokoh harus disempurnakan penampilannya dengan melihat artefak-artefak dari situs arkeologi yang lain seperti tokoh Panji yang detil perhiasannya baru diketahui setelah melihat arca dari Candi Selokelir. Tokoh Prabu Lembuamiluhur perlu dirancang dari awal untuk dapat mendekati penampilan pada masanya dengan penggunaan perhiasanperhiasan dari masa-masa yang dekat dengan masa Kerajaan Kediri. Terdapat pula adegan tari, bangunan, dan cara berpakaian yang diambil dari relief Candi Borobudur karena minimnya peninggalan fisik bangunan dari Kerajaan Kediri. Untuk perancangan komik berdasarkan relief candi selanjutnya sebaiknya juga melakukan lebih banyak observasi artefak-artefak yang satu masa dengan candi yang bersangkutan karena relief hanya menggambarkan obyek secara garis besar terutama relief-relief yang telah aus, sedangkan artefak dapat menunjukkan detildetil yang tak dapat ditampilkan atau mudah aus dalam relief.

\section{DAFTAR PUSTAKA}

[1] Balai Konservasi Borobudur. 2016. Cerita Bergambar Relief Karmawibhangga Candi Borobudur Buku Pertama. ed. Brahmantara, Jati Kurniawan, dan Aisyah Hilal. Borobudur: Balai Konservasi Borobudur Direktorat Jendral Kebudayaan Kementrian Pendidikan dan Kebudayaan.

[2] Baried, Siti Baroroh et al. 1987. Panji: Citra Pahlawan Nusantara. ed. Farid Hadi dan S.R.H. Sitanggang. Jakarta: Pusat Pembinaan dan Pengembangan Bahasa Departemen Pendidikan dan Kebudayaan.

[3] Endarto, Deddy. 2011. "Mahkota Kerajaan, Abad Ke-10 Era Kerajaan KAHURIPAN." Wilwatikta Online Museum.

https://wilwatiktamuseum.wordpress.co m/2011/12/29/mahkota-nusantaramahkota-abad-ke-10-era-kerajaankahuripan/ (Oktober 26, 2017).

[4] Joel. "Gambar Umbul: Ande Ande Lumut." Laba-Laba Lapak. 
http://labalabalapak.blogspot.co.id/2013/ 07/ande-ande-lumut.html (November 29, 2016).

[5] Karsemiyatun. 1998. Transkripsi Cariyos Andhe Andhe Lumut. Yogyakarta.

[6] Kieven, Lydia. 2014. Menelusuri Figur Bertopi Dalam Relief Candi Zaman Majapahit. Jakarta: Kepustakaan Populer Gramedia.

[7] Manuaba, Ida Bagus Putra, Adi Setijowati, dan Puji Karyanto. 2013. "Keberadaan dan Bentuk Transformasi Cerita Panji." LITERA: Jurnal Penelitian Bahasa, Sastra, dan Pengajarannya 12(Nomor 1, APRIL 2013): 53-67. http://journal.uny.ac.id/index.php/litera/ issue/view/221.

[8] Moendisoera, M. Sinoe. 1930. Cariyos Andhe Andhe Lumut. Surakarta: Panti Boedaja.

[9] Nirvana Gallery. 2015. "Komik Borobudur: Pusaka Abadi nan Jaya." Tokopedia.

https://www.tokopedia.com/nirvanagalle ry/komik-borobudur-pusaka-abadi-nanjaya (November 29, 2016).

[10] Sabdacarakatama, Ki. 2008. Sejarah Keraton Yogyakarta. ed. Tim Narasi. Yogyakarta: Narasi.

[11] Soedarso, Nick. 2015. "Komik: Karya Sastra Bergambar." Humaniora 6(4): 496-506.

[12] Tabrani, Primadi. 2001. "Memahami cara berpikir dan bahasa rupa anak." Seni Rupa \& Desain 2(1): 1-14.

[13] - —. 2009. "Wimba, asal usul dan peruntukkannya." WIMBA - Jurnal Komunikasi Visual 1(1): 1-7.

[14] Wibowo, Rio. 2016. Alkisah. Jakarta: Djarum Foundation.

[15] Yofani, Regina. 2010. "BERAGAMAN TANAMAN PADA RELIEF CANDI DI
JAWA TIMUR ABAD 14 MASEHI ( Kajian Bentuk dan Pemanfaatan )." Universitas Indonesia. http://lib.ui.ac.id/file?file=digital/201608 89-RB03R107b-Beragaman tanaman.pdf. 